\title{
Exploring our practitioner and parent partnerships
}

Article

Accepted Version

Kambouri-Danos, M., Liu, J., Pieridou, M. and Quinn, S. F. (2018) Exploring our practitioner and parent partnerships. Early Years Educator (EYE), 19 (10). pp. 26-29. ISSN 1465931X doi: https://doi.org/10.12968/eyed.2018.19.10.26 Available at https://centaur.reading.ac.uk/82764/

It is advisable to refer to the publisher's version if you intend to cite from the work. See Guidance on citing.

Identification Number/DOI: https://doi.org/10.12968/eyed.2018.19.10.26

$<$ https://doi.org/10.12968/eyed.2018.19.10.26>

Publisher: Mark Allen Group

All outputs in CentAUR are protected by Intellectual Property Rights law, including copyright law. Copyright and IPR is retained by the creators or other copyright holders. Terms and conditions for use of this material are defined in the End User Agreement.

www.reading.ac.uk/centaur

\section{CentAUR}

Central Archive at the University of Reading 
Reading's research outputs online 


\title{
Exploring our practitioner and parent partnerships
}

\author{
Maria Kambouri-Danos ${ }^{1}$, Jie Liu ${ }^{1}$, Myria Pieridou ${ }^{2}$, Suzanne Flannery Quinn ${ }^{3}$ \\ ${ }^{1}$ University of Reading, ${ }^{2}$ The Open University, ${ }^{3}$ University or Roehampton
}

\section{Introduction}

The partnership between practitioners and parents $/$ carers $^{1}$ in the early years has a significant impact on children's development, both during (Desforges \& Abouchaar, 2003) and before school age (Melhuish et al., 2008; Evangelou, Brooks \& Smith, 2007). Parents are the most important part of children's early lives, as they are the first point of reference when it comes to children's interactions with the world and they also communicate meaning and knowledge with children before and after they enter into institutional settings (e.g. nurseries or child care). In effect, collaboration between practitioners and parents is important, and when it is effective and meaningful this means that both parties are working together to achieve common goals; through mutual respect and recognition of the contribution each key agent makes towards children's development (Baum \& McMurray-Schwarz, 2004).

The study ${ }^{2}$ presented here is underpinned by Froebel's pedagogy and principles; acknowledging the importance and value of the relationship between children, family members and practitioners, and the role of play as a central, integrating element in children's development and learning (Froebel, c1826, trans 1912). For Froebel, parents and family members form the basis for a child's understandings and interactions, which reiterates that an effective partnership essentially involves the engagement of parents and practitioners in order to support all children educationally, socially and emotionally.

\section{Research methods}

The focus of the study was on the empowerment of practitioner-parent partnerships, recognising the complexity of their relations, and the positive impact a constructive partnership may have for children, their learning outcomes and their overall well-being. To encourage and support the development of this constructive relationship, the study focused on understanding parents and participants by exploring their ideas, perceptions and experiences in relation to practitioner-parent partnerships. To do this, the research team used questionnaires (the study included other elements and additional methods of data collection, but this paper focuses on the questionnaire due to word count limitation).

\footnotetext{
${ }^{1}$ Whenever referring to parents we also mean carers.

${ }^{2}$ Funded by The Froebel Trust
} 
The questionnaire was sent out through Survey Monkey to all parents and practitioners of five settings in Berkshire. A total of 109 responses were received which gives a response rate of 43.6\%. The questionnaires provided a substantive amount of quantitative data which helped to understand participants' experiences and comprehend the meaning they make of that experience. Before sending out the questionnaires, the project was approved by the University of Reading ethics committee and all participants in the project were aware of the study's aims and what it involved. Participation was voluntary while informed consent and anonymity were ensured in addition to confirming that the participants were aware of their right to withdraw from the study at any time.

\section{Preliminary Findings}

As the project is still ongoing, this paper provides a summary of the preliminary data analysis of the questionnaires. The questionnaire data very clearly suggest that both the parents and the practitioners (about 80\%) feel that they are either very interested in practitioner-parent partnerships, with more than half of them feeling extremely interested. In addition, both parents $(53 \%)$ and practitioners (55\%) feel that the daily face to face communication or parent meetings are the main way of communication with each other. However, $75 \%$ of the practitioners consider home visits as a good means of communication, while only $12.36 \%$ parents agreed to this (Figure 1). The same pattern of discrepancy was also found in the post-session questionnaire (practitioners $=58.33 \%$ while parents $=23.08 \%$ ). This might be because not all families receive a home visit which may lead to parents having different perceptions of 'home visits'. For those families who did receive a home visit from the setting, the quality of the conversation and/or the outcome of the visit is worth looking into.

Figure 1: Means of communication currently used at setting

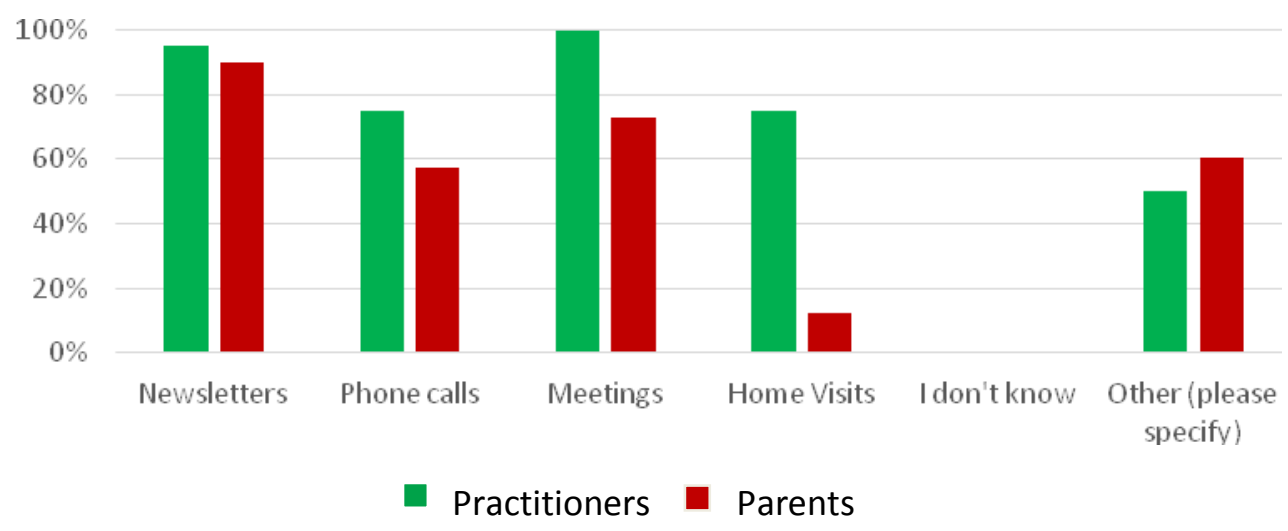


Furthermore, there were evidence that some settings occasionally consider and try out new ways of communication, such as social media (Facebook, Twitter), while they also look for additional attempts to engage in conversations around the learning taking place in the setting, without necessarily focusing or routines e.g. eating, sleeping etc. Having said this, data also reflect that in some settings, managers may feel hesitant to make use of such open access platforms online (e.g. social media or other websites), possibly because of previous communication problems experienced by the nursery.

In relation to how practitioners and parents perceive their communication and their own role in developing effective practitioner-parent partnerships, it is interesting to note differences documented between them. Initially, it was noted that practitioners perceive 'Sports Day' (45\%) and 'Fundraising Events' (65\%) as two good ways to involve parents in their children's learning experiences and to empower the parent-practitioner partnership. Nevertheless, parents do not feel the same, since only $15.73 \%$ and $25.84 \%$ of them agreed that 'Sports Days' and Fundraising Events (Figure 2) are a good way to involve parents.

Figure 2: How does the setting currently involve parents in the children's learning experiences

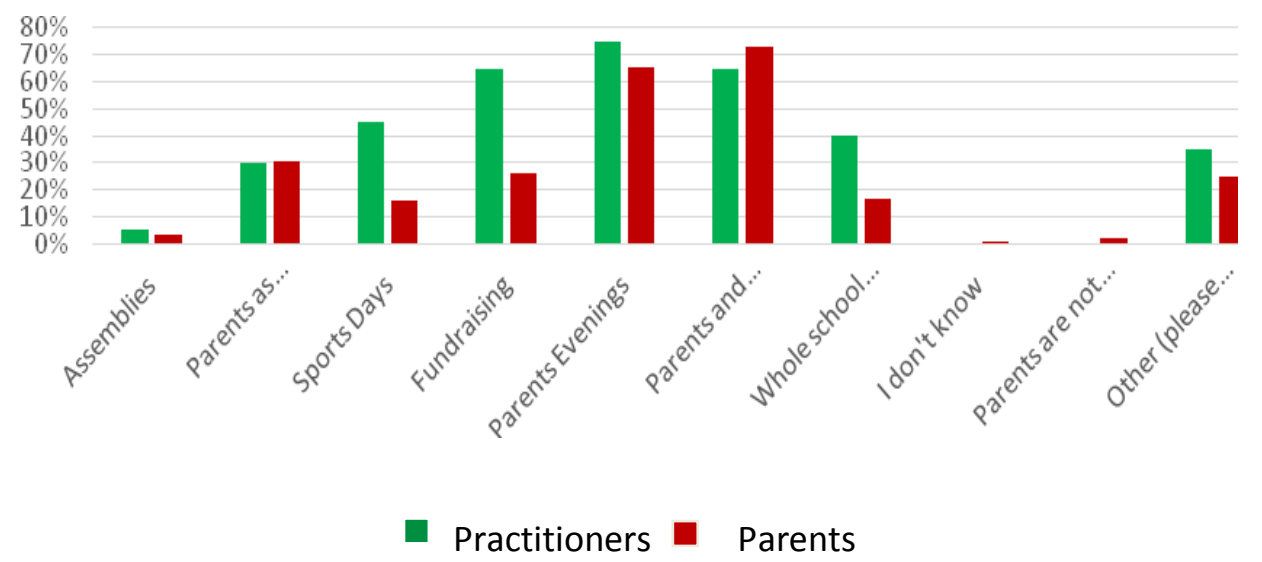

Furthermore, while $40 \%$ of the practitioners think the main way of involving parents in the children's learning experiences is to have parents' meetings or face to face chats, only $26 \%$ of the parents agree. In fact, $35 \%$ of the parents think that activities such as 'Stay and Play' sessions are more important for them and their children. The same view is shared by $35 \%$ practitioners for the 'Stay and Play' sessions, but at the same time the same percentage of practitioners consider fundraising, fairs or any social events as equally important in involving the parents in children's learning experiences.

Looking the 'Face to Face Meetings' and the identification of parental needs more closely, it appears that the majority of parents $(55.04 \%)$ do not identify this as an effective way of identifying 
parental needs, even though the vast majority of practitioners $(90 \%)$ see this as the main way to identify parents' needs. Instead, over half of the parents think that either 'Word of Mouth' or 'Surveys' are the most common way of identifying parental needs, while many of them (11.93\%) feel that there are no specific efforts to identify their needs at all. This may suggest that when the two parties formally meet, parents may find it difficult to discuss their specific needs directly with the practitioners. Yet, an informal chat or an anonymous/non-direct way of communication, such as surveys, might make it easier for parents to express their thoughts and be more sincere and open about their needs.

Finally, it is important to note that practitioners believe that lack of time, both on behalf of parents $(40 \%)$ and practitioners $(35 \%)$ is the main barrier to empowering practitioner-parent partnerships (Figure 3). Parents also acknowledge their own lack of time or availability during the settings' opening hours (66\%), rather than the practitioners' lack of time (Figure 4). Also, $10 \%$ of parents think that the practitioners need to be been more proactive or highlight more the importance of the partnership between parents and practitioners, by offering more opportunities for sharing information and for encouraging active parental involvement.

Figure 3: Main barriers identified by the practitioners

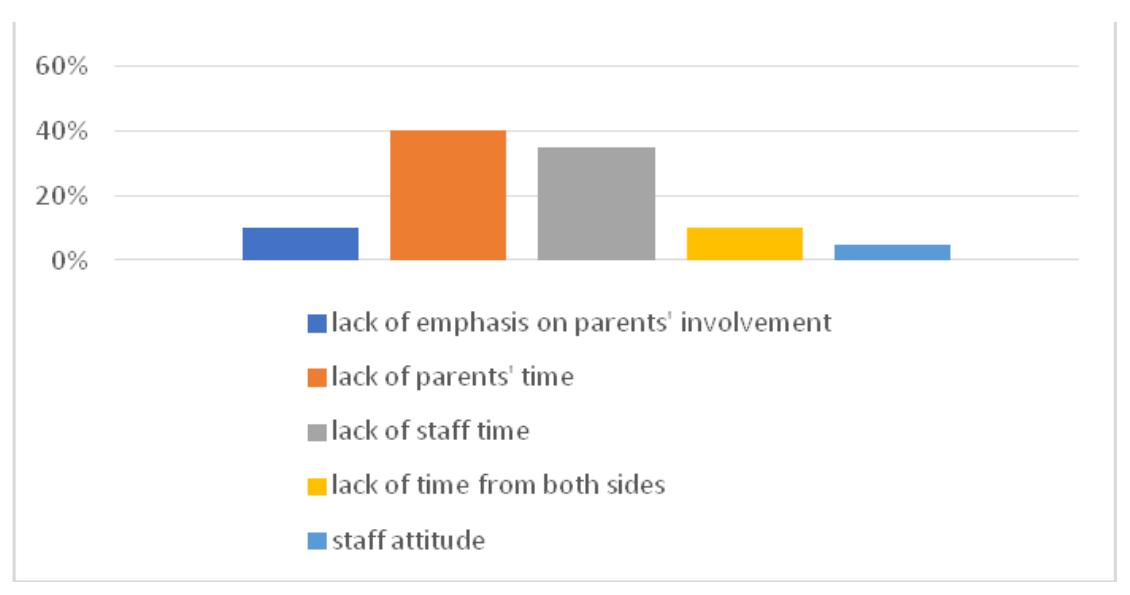

Figure 4: Main barriers identified by the parents

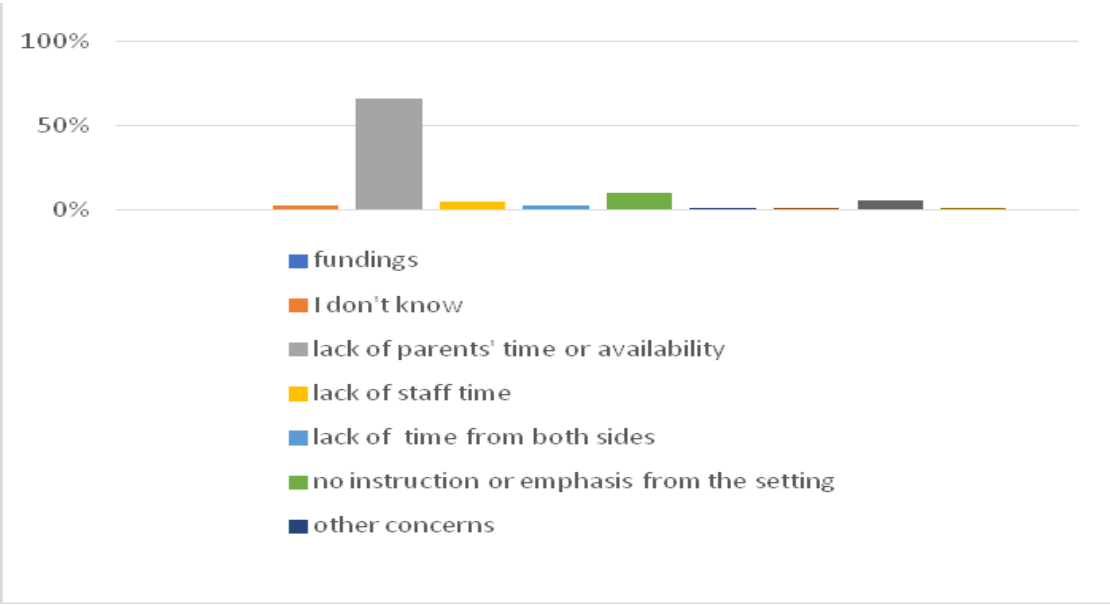


It becomes clear from the results that parents and participants share a mutual understanding of the importance partnerships hold, and both recognise that its effectiveness requires mutual respect and recognition of the contribution each party makes towards children's development (Baum \& McMurray-Schwarz, 2004). It is also evident that both parties recognise that effective and meaningful collaboration and communication is an essential part of successful partnerships (Ainscow \& Sandill, 2010), while both parents and practitioners recognise that collaboration involves reflection, exchange of knowledge and coming together to share experiences and ideas and to support the children.

Nevertheless, even though there is an accepted understanding of the role parents can take, which includes talking, listening, role modelling and managing expectations, as well as ensuring school attendance (Muschamp, Wikeley, Ridge \& Balarin, 2007), practice often falls short of this ideal (Epstein et al., 2009; Wilson, 2015). Unfortunately, this can be the case even though partnerships have a solid theoretical background and are supported both rhetorically and by legislation by the Department of Education in the UK, due to a variety of reasons such as the challenges faced when performance in schools is prioritised over other things (Rogers, 2007). In addition, this is often because some educational settings may not promote effective and meaningful partnership opportunities between practitioners and parents (Phtiaka, 2008; Baum \& MontgomerySchwartz, 2004). The results of this study support the above and show that additional barriers to effective partnerships include practitioners' and parents' everyday busy lives and routines, indicating the lack of time, but also past negative experiences, as well as different interpretations of what an effective partnership is and how it can take place (Pieridou, 2013).

\section{Conclusion}

This paper has synoptically presented the preliminary analysis of the data collected through questionnaires in a Froebel Trust funded study on practitioner - parent partnerships. Our investigation of the parents' and practitioners' views on partnership has provided us with insights on how to further support these key agents in working effectively together with the children's' best interests in mind. The results demonstrate the multidimensional character of practitioner-parent partnership, as the evidence gathered indicate that many complex yet dynamic contextual factors shape and determine practitioner-parent partnerships. The study acknowledges this complexity and suggests for parents and practitioners to have systematic opportunities to discuss and share ideas, in order to develop trust relationships and constructive partnerships between them. 
It is worth pointing out that the data and the discussion presented at this point is indicative rather than conclusive, as the study is still ongoing, the questionnaire data continue to be analysed to identify patterns between practitioners' and parents' views, while they will also be discussed with the interview data the research team has collected.

Nevertheless, one theme has become evident, that practitioner-parent partnership is a continuous and dynamic process which is subject to a wide range of contextual factors, such as spaces to get together, barriers to collaboration, and time management to name a few. In this process, mutual contributions from both sides; practitioners and parents, are essential, so as to develop a meaningful partnership, which could be facilitated by both parties being more proactive in exploring effective ways of communication, rather than waiting for the other one to take the initiatives. In order to ensure success in the development of partnerships, there is a need for settings a) to acknowledge and take action on barriers to collaboration, such as the changing demands on family life and the increase in demands upon practitioners, and b) to strengthen enablers to collaboration, such as the use of a range of methods to facilitate communications and the encouragement of a shared vision of what practitioner-parent partnerships will look like.

\section{Reference List}

Ainscow, M., \& Sandill, A. (2010). Developing inclusive education systems: The role of organisational cultures and leadership. International Journal of Inclusive Education, 14(4), 401-416.

Baum, A.C., \& McMurray-Schwarz, P. (2004). Preservice teachers' beliefs about family involvement: Implications for teacher education. Early Childhood Education Journal, 32 (1), 57-61.

Desforges, C. \& Abouchaar, A. (2003). The Impact of Parental Involvement, Parental Support and Family Education on Pupil Achievements and Adjustment: A Literature Review RR433. London: DfES.

Epstein, J. L., Sanders, M. G., Simon, B. S., Salinas, K. C., Jansorn, N. R. \& Van Voorhis, F. L. (2009). School, family, and community partnerships: Your handbook for action (3rd, ed.). Thousand Oaks, CA: Corwin Press.

Evangelou, M., Sylva, K. \& Kyriacou, M. (2009). Early years learning and development: Literature review. London: DCSF

Froebel F. (c1826, trans. 1912). Froebel's Chief Writings on Education (Rendered into English) S. S. F. Fletcher and J. Welton (trans). London: Edward Arnold.

Melhuish, E.C., Mai B. Phan, M.P., Sylva, K., Sammons, P., Siraj-Blatchford, I. \& Taggart, B. (2008). Effects of the home learning environment and preschool centre experience upon literacy and numeracy development in early primary school. Journal of Social Issues, 64(1), 95-114. 
Muschamp, Y., Wikeley, F., Ridge, T. \& Balarin, M. (2007). Parenting, Caring and Educating. Primary Review Research Study 7/1. Interim Report. Cambridge: University of Cambridge. Available at: http://core.kmi.open.ac.uk/download/pdf/309511.pdf

Phtiaka, H. (2008). Drop by for a coffee: Family and school relationships at the edges of diversity. Athens: Taxideutis (In Greek)

Rogers, C. (2007). Experiencing an 'inclusive' education: parents and their children with 'special educational needs', British Journal of Sociology of Education, 28(1), 55-68.

University of Reading. (2012). University code of good practice in research. Available at: http://www.reading.ac.uk:8081/web/FILES/reas/UCOGPR_UBRlappro25Nov13.pdf 